Changes in Meal Participation, Attendance, and Test Scores Associated with the Availability of Universal Free School Breakfasts

Author(s): David C. Ribar and Lauren A. Haldeman

Source: Social Service Review, Vol. 87, No. 2 (June 2013), pp. 354-385

Published by: The University of Chicago Press

Stable URL: http://www.jstor.org/stable/10.1086/671013

Accessed: 24/10/2013 16:15

Your use of the JSTOR archive indicates your acceptance of the Terms \& Conditions of Use, available at http://www.jstor.org/page/info/about/policies/terms.jsp

JSTOR is a not-for-profit service that helps scholars, researchers, and students discover, use, and build upon a wide range of content in a trusted digital archive. We use information technology and tools to increase productivity and facilitate new forms of scholarship. For more information about JSTOR, please contact support@jstor.org. 


\title{
Changes in Meal Participation Attendance, and Test Scores Associated with the Availability of Universal Free School Breakfasts
}

DAVID C. RIBAR AND LAUREN A. HALDEMAN University of North Carolina at Greensboro

\begin{abstract}
This study investigates student outcomes associated with changes in the availability of universal free breakfasts at elementary schools in the Guilford County Schools (GCS) in North Carolina. In 2007-8, the GCS offered universal free breakfasts in schools with high proportions of economically disadvantaged students. In 2008-9, the GCS reduced its universal free programs, with the affected schools returning to eligibility-based programs. We examine how breakfast and lunch participation, attendance, and reading, math, and science test scores changed across years at affected and unaffected schools. We find that the switch from a universal free to an eligibility-based School Breakfast Program reduced breakfast participation substantially with the largest changes occurring among students who were not eligible for free or reduced-price meals. The changes to eligibility-based provision were associated with decreases in lunch participation for paid-eligible students but not for other students. The changes to eligibility-based provision did not harm test scores or attendance.
\end{abstract}

\section{N T ROD U C T I O N}

The School Breakfast Program (SBP) is intended to provide children with healthy meals to help their school performance and nutritional well-being. The program offers free and reduced-price breakfasts to children from low-income households and subsidizes breakfasts for other children. The federal government provides cash subsidies and in-kind support for the program, and school systems (school food authorities, or SFAs) operate and administer the programs, often contributing funding of their own. In fiscal year 2009, the SBP served more than 11 million children at a federal cost of \$2.6 billion (US Economic Research Service 2010).

Social Service Review (June 2013). (c) 2013 by The University of Chicago. All rights reserved. 0037-7961/2013/8702-0006\$10.00 
The eligibility guidelines for the SBP are the same as the National School Lunch Program (NSLP). Children are categorically eligible for free meals if they live in a household that receives benefits from the Supplemental Nutrition Assistance Program or the Temporary Assistance for Needy Families program. They are also eligible for free meals if they live in a household with an income below 130 percent of the federal poverty guidelines and eligible for reduced-price meals if they live in a household with an income between 130 and 185 percent of the guidelines.

Although the SBP and NSLP share the same eligibility criteria, participation in the breakfast program has been substantially lower than participation in the lunch program. The differences in participation arise from lower participation by schools in the SBP but also from lower participation by students at schools that offer breakfasts. To encourage SBP participation, some schools and SFAs have offered universal free school breakfasts, serving free breakfasts to all children at a school regardless of eligibility. Schools can do this with federal funding under special provisions of the National School Lunch Act (US Food and Nutrition Service 2001) or with state or local funding. Some of these schools, however, are finding that they can no longer afford universal free programs. Susan Bartlett, Frederic Glantz, and Christopher Logan (2008) report that the full cost of providing a breakfast at an average SFA in 2005-6 exceeded the most generous federal reimbursement rate by nearly a dollar. Rising food prices in subsequent years and deteriorating budget conditions during the Great Recession also led schools to revisit their universal free breakfast policies.

In this study, we investigate student outcomes associated with changes in the availability of universal free breakfasts at elementary schools in the Guilford County Schools (GCS) in North Carolina. In 2007-8, the GCS offered universal free breakfasts in 26 schools with high proportions of economically disadvantaged students. In the following year, budgetary pressures and a reinterpretation of state policy led the GCS to change to eligibilitybased SBPs at three elementary schools, while adding a universal free SBP at one other elementary school.

We examine several types of student outcomes with data drawn from different administrative sources: counts of breakfasts and lunches served by each school from the GCS, attendance rates for each school grade from the North Carolina Department of Public Instruction (NCDPI), and standardized test score and additional attendance information for individual students from the North Carolina Education Research Data Center (NCERDC). 
These outcomes relate to the food consumption and school performance objectives of the SBP. As Lawrence Bernstein and colleagues (2004) show, they are also conceptually linked.

In particular, we expect the change from universal free to eligibilitybased provision to discourage SBP participation in two ways. First, the imposition of a fee creates an economic disincentive among children who would not otherwise qualify for free meals. Second, the change may further discourage participation, including participation among free-eligible students, by increasing the stigma and reducing the peer acceptance of school breakfasts. Frederic Glantz and colleagues (1994), among other researchers, report that stigma is a significant barrier to SBP participation.

By lowering breakfast participation, the return to eligibility-based provision may affect other outcomes. For example, increased stigma or lower peer valuations may extend to school meals generally, leading to a decrease in NSLP participation. Alternatively, reductions in breakfast consumption may make school lunches more attractive (or necessary). Participation in the SBP might also affect attendance. Because the meals are served at school, the SBP confers an extra benefit on attendance. The incentive may be weak, however, because it comes on top of compulsory schooling requirements and the value of school itself. Also, it is possible that SBP participation could adversely affect attendance if, for instance, cafeteria settings increase the transmission of contagious illnesses (Cauchemez et al. 2011).

Changes in school meal consumption could also affect cognitive outcomes. In principle, SBP participation should lead to fewer skipped meals and increase the quality of children's breakfasts. These changes could lead to short-term metabolic improvements or longer-term health gains that might, in turn, contribute to better cognitive outcomes and academic success. The first link in this chain, however, is key: to improve cognitive performance, SBP participation must increase the consumption and quality of breakfasts and not merely replace meals the children would have received from home. Because levels of breakfast consumption are moderately high, there is very limited scope for change and thus for cognitive impacts. ${ }^{1}$

1. The US Agricultural Research Service (2010) estimates that about one in nine elementary-school-aged children skipped breakfast on any given day in 2007-8. This rate rose to one in six for children who were living in households with incomes between 130 and 185 percent of the poverty line. An analysis of the SBP Pilot Project (Bernstein et al. 2004) fails to find statistically significant differences in most types of dietary components between 
Our study adds to a large research literature on universal free school breakfast provision. As we discuss below, the studies in this area generally find that universal free provision increases breakfast participation. However, estimates of effects on attendance, test scores, and other outcomes are equivocal, leaving room for additional research. Our empirical methodology has several strong elements. First, it relies on a quasiexperimental source of program variation, at least from the perspective of the students, reducing the chances that our statistical results are confounded by student and household characteristics that are associated with meal participation and the outcomes of interest. Second, we analyze administrative data, which are not subject to recall errors, strategic or socially motivated misreporting, or selective cooperation. Third, most of the data are available longitudinally, allowing us to compare outcomes before and after the change in SBPs at affected and unaffected schools; that is, we are able to conduct difference-in-difference analyses. We increase the comparability of the schools by matching the affected schools with unaffected schools that had similar programmatic and demographic characteristics and that were located in nearby neighborhoods.

Our data have some other unique features. First, they include a contraction of services from universal free to eligibility-based provision, while previous research on universal free SBPs mainly examines expansions. Participation changes may differ in expanding and contracting environments if, for instance, parents and students are slow to discover the availability of a new universal free SBP but immediately confront the consequences of a change to an eligibility-based program. Second, our data are very recent. Our study joins just a few others (Bernstein et al. 2004; Peterson et al. 2004; LeosUrbel et al. 2011) in examining student outcomes under the higher nutritional standards set by the US Department of Agriculture in 1995 under its School Meals Initiative.

\section{SCHOOL BREAKFASTS IN THE GUILFORD COUNTY SCHOOLS}

The GCS in North Carolina is a moderately large school system, with 119 schools and more than 70,000 students. The GCS covers all of Guilford County (population 450,000), including the cities of Greensboro (pop-

students who attended schools that operated eligibility-based or universal free SBPs in nonclassroom settings. 
ulation 237,000) and High Point (population 98,000). ${ }^{2}$ The system's student population is ethnically diverse: 42 percent of the students are white, 41 percent are black, 8 percent are Hispanic, 5 percent are Asian, and the rest are composed of other groups. Just under half of the students in the GCS are eligible for free or reduced-price meals.

The GCS operates breakfast programs throughout the system. Most GCS elementary schools operate eligibility-based SBPs. In 2007-8 and 2008-9, breakfasts at those schools were offered for free, for 304 if the student qualified for reduced-price meals, or for $90 \phi$ if the student did not qualify for free or reduced-price meals. Breakfasts included choices of milk, juice, and cereal in addition to a fruit serving and a breakfast entrée.

North Carolina allows school districts to operate universal free SBPs at individual schools if those schools can do so without a loss (that is, if they can cover the costs with the federal subsidies). ${ }^{3}$ In academic year 2007-8, the GCS used this flexibility to operate universal free breakfast programs in 26 Title I schools in which at least 70 percent of the students were expected to qualify for free or reduced-price meals. ${ }^{4}$

Early in 2008, GCS officials became concerned that the conditions that were necessary to operate universal free SBPs might not be met because of rising food prices and increasing breakfast participation. That summer, the GCS altered its formula for selecting schools that would offer universal free programs. ${ }^{5}$ These changes resulted in the GCS switching to eligibility-based programs at three elementary schools and one middle school that initially offered universal free programs. The GCS also began offering universal free breakfast at one elementary school that initially

2. Guilford County has had a unified, county-wide school district since 1993. Before consolidation, separate school districts covered Greensboro, High Point, and the balance of Guilford County.

3. North Carolina also subsidizes universal free breakfasts for kindergarten students at selected schools. All of the GCS elementary schools with "general" universal free SBPs participate in the universal free kindergarten program.

4. Title I of the Elementary and Secondary Education Act of 1965 provides supplemental federal funding to schools with high numbers or proportions of economically disadvantaged students.

5. In 2007-8, the GCS used revenues (federal subsidies) from free and reduced-price meals to calculate whether schools would break even in providing universal free meals; in 2008-9, the GCS only used revenues from free meals. The GCS also slightly altered its projection of participation growth associated with offering universal free programs to assume 15 percent growth. 
had an eligibility-based program. Because the sole source of these changes was the modification of the selection formula (no schools would have switched under the old formula), the changes constitute a natural experiment.

\section{PREVIOUS RESEARCH}

Breakfast is often called the most important meal of the day, a reputation that stems partly from a substantial body of research that links breakfast consumption to positive outcomes for children. Gail Rampersaud and colleagues (2005) recently conducted a systematic review of scientific studies of the effect of breakfast consumption on nutritional status, weight, cognitive performance, and academic outcomes. Alexa Hoyland, Louise Dye, and Clare Lawton (2009) conducted a similar review of cognitive studies. The evidence is far from uniform but, on balance, indicates that breakfast consumption is associated with better nutritional outcomes for children and a lower incidence of being overweight or obese. Evidence regarding cognitive outcomes is more equivocal. Several studies find a relationship between breakfast consumption and performance in short-term memory tasks but are less clear regarding whether breakfast improves longer-term academic performance. To the extent that relationships exist, they tend to be strongest in children who are at the highest nutritional risk. There is scant direct evidence that marginally improving breakfast quality (e.g., changing a few breakfast items) has noticeable effects on cognitive outcomes.

David Connell and Mary Fox (2004) summarize numerous evaluations of the SBP that had been conducted through 2004, including several evaluations of universal free programs. There is consistent evidence that universal free programs increase school breakfast participation. Beyond that, the findings across studies diverge. Several studies have found that universal free SBPs are associated with better nutritional outcomes, improved short-term cognitive performance, greater attendance, and higher academic achievement. For example, J. Michael Murphy and colleagues (1998) and Ronald Kleinman and colleagues (2002) examine the implementation of universal free SBPs at three schools using pre- and postcomparisons and find a near doubling of breakfast participation rates and evidence that participation is associated with lower absenteeism and higher math grades.

Some other recent studies with stronger research designs also report positive educational and behavioral outcomes. Michèle Belot and Jona- 
than James (2011) evaluate a campaign to improve the quality of school meals in the United Kingdom and find that the campaign improved attendance and test scores. Christelle Roustit and colleagues (2010) investigate how the availability of school meal programs in Canada affects scholastic performance. They report that these programs eliminate scholastic gaps between children living in food insecure and food secure households.

Other recent studies fail to detect associations for schooling outcomes. The most notable is the SBP Pilot Project (Bernstein et al. 2004), a largescale, random-assignment evaluation of universal free programs in six school districts. Results from this experiment indicate that offering free breakfasts boosts participation but does not lead to a consistent pattern of improvements in nutrition, attendance, or cognitive outcomes. Kristin Peterson et al. (2004) examine the implementation of universal free programs in Minnesota schools. Consistent with other research, they find sizable gains in SBP participation. However, they find only weak evidence of test score impacts and some evidence of increased absenteeism. Simon Murphy and colleagues (2011) investigate the effects of universal free programs on breakfast consumption, meal attitudes, episodic memory, and class behavior in a random-assignment trial in Wales. They find that the programs improved diets and meal attitudes but had no other effects on student outcomes. Jacob Leos-Urbel and colleagues (2011) examine the implementation of universal free SBPs in New York City and find only weak evidence that they improved test scores.

Another study points to the difficulties in trying to draw causal inferences from the associations between school meal operations and student outcomes. David Figlio and Joshua Winicki (2005) examine menus for schools in Virginia during weeks when students were and were not taking high-stakes tests. They find that the menus differed systematically, suggesting that schools manipulated the calorie and nutritional content of meals in an attempt to improve test performance.

The methodologies of the different studies vary. Our investigation shares several key features with some of the most recent studies. In particular, we examine student outcomes associated with a quasi-experimental change in school breakfast provision. We use a pre- and postchange design but also compare outcomes across schools that did and did not change their SBPs. A distinctive feature of our study is that it examines changes from universal free to eligibility-based programs; previous evaluations consider changes in the other direction. 


\section{A T A}

To examine how school meal participation, school attendance, and test score performance vary with the availability of universal free breakfast programs, we relied on a number of different data sources, including administrative records from the GCS School Nutrition Services office, publicly available information from the NCDPI, and confidential information from the NCERDC. The measures from each source are summarized in the appendix.

\section{MEAL PARTICIPATION}

The GCS provides data on monthly counts of the breakfasts and lunches each school served to students who were eligible for different types of subsidies. The raw counts are difficult to compare, as they vary with characteristics such as the total enrollment, the composition of reduced-price and free-eligible students, and the number of days on which particular types of meals were served. To address these issues, we express the meal figures in terms of participation rates, where

$$
\text { participation }=\frac{\text { meals served in the period }}{\text { students in daily membership } \times \text { school days in period }} \text {. }
$$

For example, to calculate a school's breakfast participation rate among free-eligible students in a given month, we divide the number of breakfasts served to free-eligible students during that month by the product of the number of free-eligible students in daily membership and the number of days that month that breakfasts were served. The participation rate gives the approximate average daily proportion of students of a given eligibility group taking a particular type of meal over the specified period. We calculate participation rates for all breakfasts and all lunches and participation rates for each type of meal by eligibility status (free breakfasts, free lunches, reduced-price breakfasts, etc.).

\section{ATTENDANCE}

We examine student attendance data from two sources. First, the Principal's Monthly Report (PMR) on attendance, available from the NCDPI, 
provides monthly counts of students in membership and in attendance by grade at each school. ${ }^{6}$ We form measures of monthly grade-specific attendance rates at the schools by dividing the number of students in attendance by the number of students in membership. For reasons of comparability with our other data sources and because the changes in SBPs were focused on children in the first grade and higher, we only analyze attendance outcomes for children in the first through fifth grades and omit children in kindergarten.

Because the grade-level attendance measures are aggregate figures, they cannot be linked to characteristics of particular students. This issue leads us to also examine student-level attendance from the NCERDC, a repository that houses confidential data from the NCDPI on test scores, attendance, and other characteristics. The NCERDC assigns internal identifiers that allow these data to be linked to schools and linked to individuals over time. We use attendance data from the spring test score files. These data indicate the number of days that the student was a member of a school as of that school's test date and the number of days on which the student was absent over the same period. A personal attendance rate is calculated as one minus the ratio of absences to membership days. The principal advantage of the NCERDC data is that they can be linked to other observable characteristics of the student and can be linked longitudinally (i.e., support before and after comparisons for the same student). The drawbacks of these data are that they capture attendance over most but not all of the year (i.e., through the testing date) and lack some covariates for first- and secondgrade students who do not take the standardized tests.

\section{TEST SCORES}

North Carolina has been using annual accountability tests to measure school performance for more than a decade. Elementary students in the state take the following end-of-grade (EOG) tests in the last 3 weeks of school: reading comprehension tests administered in the third, fourth, and fifth grades; mathematics tests administered in the third, fourth, and fifth grades; and a science test administered in the fifth grade. Results from these tests are

6. The PMR data are reported on the basis of "school months" rather than calendar months. The school months correspond to each set of 20 days that the school is open. See http://www.ncpublicschools.org/fbs/accounting/data/. 
used to determine levels of proficiency and schools' progress toward No Child Left Behind goals. Through an agreement with the NCERDC, we obtained access to student-level data for GCS elementary students in 2007-8 and 2008-9.

About five-sixths of students take the general version of the reading and math tests. However, some students who require special testing accommodations take alternative versions of the tests. For each type of test, students' scores are mapped into one of four achievement levels, with level 3 representing performance that is deemed proficient, or consistent with grade-level expectations (see NCDPI [2011] for more information about the tests). For all students who took the tests, we form binary indicators that equal one if the scores were proficient or better.

The binary proficiency measure only captures performance at one point along the score distribution and may miss changes in scores below or above this margin. To address this issue, we also examine continuous, gradestandardized scores of the general versions of the reading and math tests and raw scores from the general version of the science tests. ${ }^{7}$ As mentioned, the students who took the general versions of the EOG tests are a selective (more abled) group than the overall population of students. In the end, the findings are similar whether we use the binary or continuous test performance measures.

Our multivariate analyses of test scores use the student-level data. However, to avoid the inadvertent disclosure of confidential results, the descriptive analyses use publicly available information from the NCDPI report card database. In particular, the NCDPI releases the percentages of students in each relevant grade at each school whose test scores indicate that they are proficient in math, reading, and science.

\section{EXPLANATORY MEASURES}

Our multivariate analyses draw on several explanatory measures from the NCDPI and NCERDC. From the NCDPI, we obtained school-level measures of the proportions of students who were black, Hispanic, female, free-meal eligible, and reduced-price eligible. From the NCERDC, we use person-level controls for the students' race and ethnicity (black, Hispanic,

7. The science general test raw score had a possible range of 120-180. Statewide, the mean was just over 150, and the standard deviation was 9.5 . 
and other nonwhite, non-Hispanic ethnicity), gender, meal subsidization status, limited English proficiency, math or reading giftedness, and disability status.

\section{SELECTION OF SCHOOLS}

Four Title I elementary schools in the GCS underwent changes in their SBPs in 2008-9: three switched from universal free to eligibility-based programs, and one switched from an eligibility-based program to universal free. The schools were not randomly chosen and were not representative of all schools in the GCS. For our analyses, we wanted to compare outcomes at the four "change" schools to outcomes at other "nonchange" schools that matched closely in terms of their observed characteristics.

We began by considering elementary schools in the GCS that received Title I funding. Of the 65 elementary schools in the GCS in 2007-8 and 2008-9, 30 received Title I funding. We next considered school calendars and programs. Each of our change schools operated on traditional 180-day calendars, enrolled students on a regular rather than a magnet basis, and was accredited by the Southern Association of Colleges and Schools (SACS). We also wanted all of our comparison schools to be located in the cities of Greensboro or High Point, where the four change schools were located, rather than rural parts of Guilford County.

After applying all of these criteria, we were left with 18 potential comparison schools: 14 schools that had universal free programs in both years and four that had eligibility-based programs for both years. Within these sets, we looked for comparison schools that were similar in size, racial and ethnic makeup, and economic disadvantage to our change schools in 2007-8. Size was important because we wanted to examine schools with similar scales of meal operations. Race, ethnicity, and economic disadvantage are likely to be directly associated with student outcomes but also have policy significance, such as No Child Left Behind targets. Economic disadvantage also entered into the school system's selection of schools that would change their SBP status. In particular, the change schools were more economically disadvantaged than GCS elementary schools as a whole but less disadvantaged than the schools that continued to offer universal free SBPs.

Ultimately, there were six comparison schools that closely matched the size, demographic, and economic characteristics of our change schools. These include five schools that maintained universal free SBPs and one that maintained an eligibility-based program. Most of our empirical anal- 
yses focus on data from the four change and six matched-comparison schools. However, we also replicated all of our analyses using the broader set of 22 traditional-calendar, nonmagnet, SACS-accredited, Title I elementary schools. None of our findings are sensitive to the choice of comparison set (results are available on request).

Characteristics of the schools in our study, conditional on the type of breakfast programs they operated, are reported in table 1. The top half of the table lists averages of the school size (average daily membership) and percentages of students who are black, Hispanic, female, free-meal eligible, and reduced-price eligible for 2007-8. The bottom half of the table lists the same statistics for 2008-9. Column 1 shows characteristics of the three schools that switched from universal free to eligibility-based SBPs. Column 2 shows characteristics of the 14 study schools that maintained universal free programs, while column 3 lists characteristics of the narrower set of matched-comparison schools that maintained universal free programs. Columns 4-6 list characteristics for the four study schools that maintained eligibility-based programs, the comparison school that main-

TABLE 1. Characteristics of Students at Analysis Schools

\begin{tabular}{|c|c|c|c|c|c|c|}
\hline & \multicolumn{3}{|c|}{ Universal Free SBP 2007-8 } & \multicolumn{3}{|c|}{ Eligibility-Based SBP 2007-8 } \\
\hline & \multirow{2}{*}{$\begin{array}{c}\text { Eligibility- } \\
\text { Based SBP } \\
2008-9 \\
(1)\end{array}$} & \multicolumn{2}{|c|}{$\begin{array}{l}\text { Universal Free SBP } \\
2008-9\end{array}$} & \multicolumn{2}{|c|}{$\begin{array}{l}\text { Eligibility-Based } \\
\text { SBP 2008-9 }\end{array}$} & \multirow{2}{*}{$\begin{array}{c}\text { Universal } \\
\text { Free SBP } \\
2008-9 \\
(6)\end{array}$} \\
\hline & & $\begin{array}{l}\text { All } \\
(2)\end{array}$ & $\begin{array}{c}\text { Comparison } \\
\text { (3) }\end{array}$ & $\begin{array}{l}\text { All } \\
(4)\end{array}$ & $\begin{array}{c}\text { Comparison } \\
\text { (5) }\end{array}$ & \\
\hline \multicolumn{7}{|l|}{ 2007-8 characteristics: } \\
\hline Students (average daily & & & & & & \\
\hline membership) & 485 & 391 & 454 & 452 & 605 & 533 \\
\hline$\%$ students black & 68.4 & 68.5 & 66.4 & 61.0 & 51.2 & 46.5 \\
\hline \% students Hispanic & 13.3 & 17.4 & 15.7 & 14.1 & 12.4 & 24.0 \\
\hline$\%$ students female & 48.7 & 48.8 & 47.8 & 48.7 & 49.8 & 48.6 \\
\hline $\begin{array}{l}\% \text { students free eligible } \\
\% \text { students reduced-price }\end{array}$ & 66.1 & 81.8 & 79.3 & 58.4 & 55.8 & 74.2 \\
\hline eligible & 14.3 & 9.7 & 9.6 & 14.8 & 12.7 & 7.5 \\
\hline \multicolumn{7}{|l|}{ 2008-9 characteristics: } \\
\hline $\begin{array}{l}\text { Students (average daily } \\
\text { membership) }\end{array}$ & 491 & 401 & 462 & 427 & 522 & 505 \\
\hline$\%$ students black & 68.6 & 67.2 & 63.8 & 61.7 & 48.7 & 49.5 \\
\hline$\%$ students Hispanic & 14.8 & 18.5 & 17.1 & 15.5 & 14.0 & 22.8 \\
\hline$\%$ students female & 50.0 & 49.3 & 49.1 & 48.7 & 47.3 & 47.9 \\
\hline $\begin{array}{l}\% \text { students free eligible } \\
\% \text { students reduced-price }\end{array}$ & 65.2 & 81.5 & 80.9 & 56.3 & 56.3 & 72.1 \\
\hline eligible & 13.6 & 7.2 & 7.7 & 12.8 & 11.7 & 7.0 \\
\hline Schools & 3 & 14 & 5 & 4 & 1 & 1 \\
\hline
\end{tabular}

Note.-Authors' calculations from North Carolina Department of Public Instruction attendance and school report card data and from Guilford County Schools meal participation data. SBP = School Breakfast Program. 
tained an eligibility-based program, and the change school that switched to a universal free program.

The study schools with universal free breakfast programs in 2007-8 had higher proportions of minority and economically disadvantaged students than the schools with eligibility-based breakfast programs. If we consider just the schools that initially had universal free breakfast programs, we see that the change schools tended to be larger but also tended to have lower percentages of economically disadvantaged students than the nonchange schools. The smaller set of universal free comparison schools matches the change schools in terms of class size but is only marginally more comparable in terms of economic disadvantage. Among the schools that initially had eligibility-based programs, the comparison school is much closer to the change school in terms of racial composition and 2008-9 enrollment than the other schools.

In addition to these comparisons of measured characteristics, we also observed cafeteria operations at the change and matched-comparison schools and conducted focus-group interviews at several of the schools (Haldeman, Himmelrich, and Ribar 2011). The meal observations indicate that the schools operated comparable breakfast and lunch programs, giving the children similar amounts of time to eat, offering similar menus, and using similar line procedures. All of the schools operated before-school breakfast programs, and all but one served breakfasts in the cafeteria (one school served some breakfasts in the cafeteria and some in classrooms). The comparability of meal operations is important because previous research indicates that the method of SBP delivery can make a substantial difference in participation rates (Rainville and Carr 2008). The focus group discussions reveal that parents at the schools were knowledgeable about the meal programs, that they held similar attitudes regarding the value of breakfasts, that many experienced food hardships, and that they saw the school meal programs as helping to address household food needs. The principal difference between schools is that parents from the school that gained a universal free SBP spoke more positively about the school meals, while parents from schools that moved to an eligibility-based program spoke more negatively.

\section{DESCRIPTIVE ANALYSIS OF STUDENT OUTCOMES}

Table 2 lists 2007-8 and 2008-9 averages of meal participation rates, attendance rates, and test score results for schools that changed from uni- 


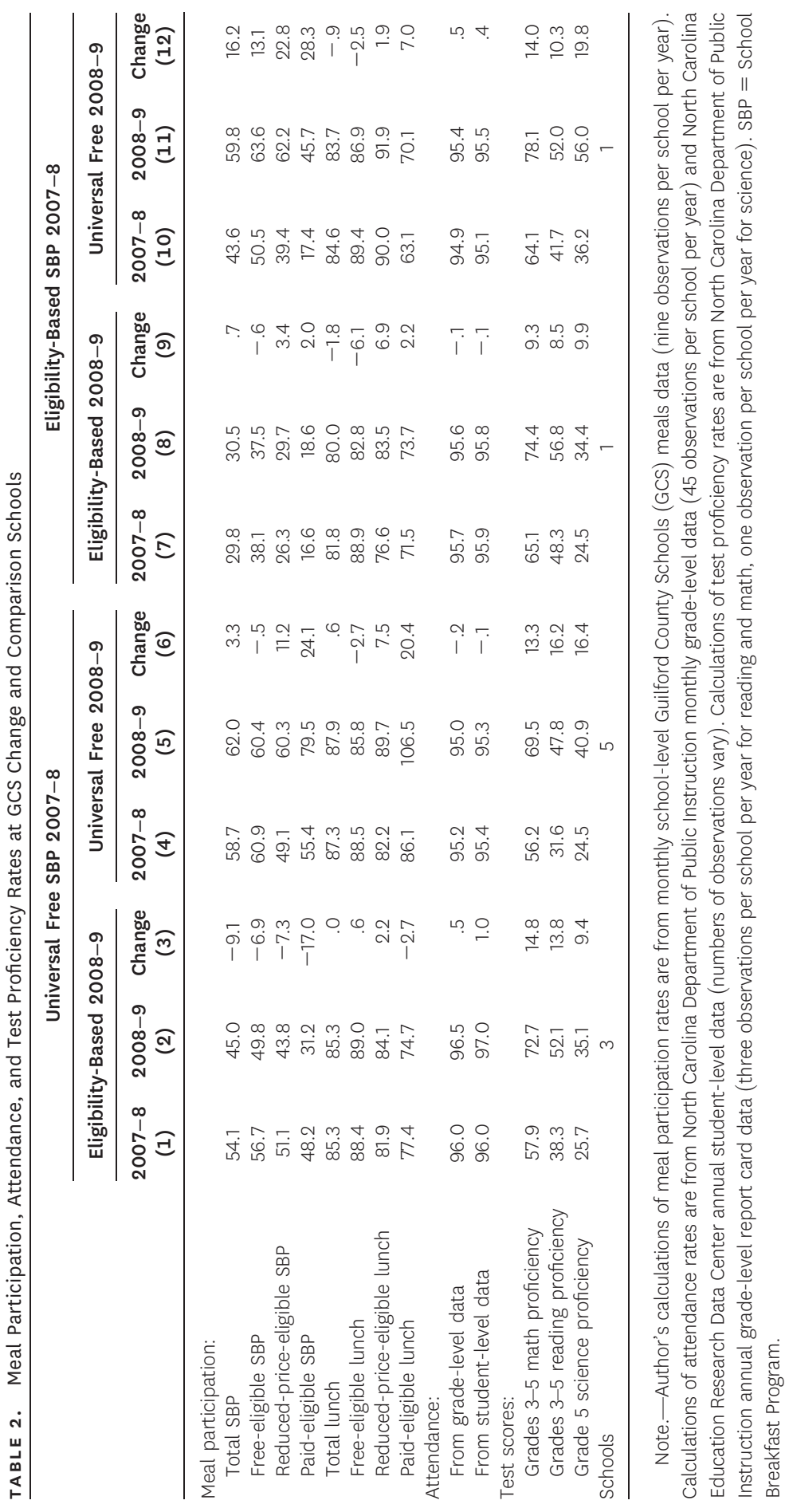


versal free to eligibility-based SBPs (cols. 1-3), the matched-comparison schools with universal free programs (cols. 4-6), the matched-comparison school with an eligibility-based program (cols. 7-9), and the school that changed from eligibility-based to universal free provision (cols. 10-12). The schools that offered universal free breakfasts had moderately high SBP participation rates, with total (all-student) participation rates ranging from 54 to 62 percent. SBP participation rates for the eligibility-based programs were much lower. The three schools that switched from universal free to eligibility-based provision experienced a 9 percent average decline in their all-student SBP participation rates. In contrast, SBP participation grew slightly at the matched-comparison schools that continued to offer universal free breakfasts. All-student SBP participation at the school that changed from eligibility-based to universal free provision grew 16 percent, while participation at the matched comparison school with an eligibility-based SBP was virtually unchanged. The comparison of trends indicates that universal free provision was associated with higher SBP participation.

When we consider the eligibility groups, SBP participation was highest among free-eligible students and lowest among paid-eligible students. Participation for each group fell faster at the schools that lost universal free programs, and grew faster at the schools that added them, than at the schools that did not change programs. The changes in participation are largest for the reduced-price and paid-eligible students but were also substantial at 7-13 percent for the free-eligible students.

Lunch participation is higher than breakfast participation in all schools and varied only modestly across the different types of schools. Participation is highest at the schools that maintained universal free breakfast programs and lowest at the school that maintained an eligibility-based program. Much of the difference in levels of lunch participation can be traced to differences in the composition of eligibility groups across schools. Lunch participation rates were very similar within eligibility groups at the different schools. The figures also point to a data issue: estimated paid-eligible lunch participation exceeded 100 percent in 2008-9 at the matched-comparison schools that maintained universal free SBPs. This problem appears to be an artifact of the small numbers of paid-eligible students at some matchedcomparison schools and of the distribution of eligible students only being measured at one point during the school year. ${ }^{8}$

8. The numbers of free- and reduced-price-eligible students appear to be counts of students who ever had this status during the year. If a student became free or reduced-price eligible 
Lunch participation fell among free-eligible students, except at the schools that changed from universal free to eligibility-based SBPs. Lunch participation generally increased among reduced-price and paid-eligible students, except for paid-eligible students at schools that changed from universal free to eligibility-based SBPs. ${ }^{9}$

Attendance increased at the three schools that switched from universal free to eligibility-based provision of breakfasts. However, attendance also increased at the school that switched from eligibility-based to universal free provision. In contrast, attendance fell slightly at the schools that did not experience changes in their breakfast programs. ${ }^{10}$

The last three rows in table 2 show that the percentages of students whose scores on their EOG math, reading, and science tests met the state's proficiency levels increased across all the schools. However, there are no consistent patterns in the differences in growth rates across different types of schools. For example, math proficiency increased more at the elementary schools that switched from universal free SBPs to eligibility-based SBPs than at the matched-comparison schools that maintained universal free SBPs, but reading and science proficiency showed the opposite patterns.

\section{MULTIVARIATE ANALYSES OF STUDENTOUTCOMES}

We estimate multivariate, difference-in-difference regression models for our various student outcomes. For our analyses of aggregate outcomes, let $A_{g, s, y, m}$ represent an aggregate outcome (meal participation or attendance) for student group $g$ at school $s$ in month $m$ of year $y$. We assume that the outcome depends on whether universal free or eligibility-based school breakfasts were offered; let $U_{s, y}$ be a binary variable that indicates the avail-

during the year, she could have received some paid meals but would not appear as a paid-eligible student.

9. In a longer report (Ribar and Haldeman 2011), we also considered how meal participation changed on a month-by-month basis. SBP participation in the opening month of 2008-9 increased at all of the schools. The absence of differences across schools likely reflects the GCS accommodating students whose meal eligibility was being determined. At the schools that switched their SBPs, the changes in participation became evident by October and continued through the rest of the year. There were few changes in lunch participation rates across the schools.

10. We also examine the attendance on a month-by-month basis (Ribar and Haldeman 2011). Those analyses indicate that the increases in attendance at the change schools were largest around January and February. 
ability of universal free breakfasts at school $s$ in year $y$. We also assume that the outcome depends on other measured characteristics of the student group, $X_{g, s, y}$; unmeasured month- and year-specific characteristics (seasonality and time fixed effects), $\kappa_{m}$ and $\tau_{y}$; unmeasured time-invariant characteristics of the school (school group fixed effects), $\eta_{s}$; and other unmeasured timevarying and individual-/group-specific characteristics, $\varepsilon_{g, s, y, m}$. We estimate models of the form

$$
A_{g, s, y, m}=\alpha U_{s, y}+\beta X_{g, s, y}+\kappa_{m}+\tau_{y}+\eta_{s}+\varepsilon_{g, s, y, m}
$$

where $\alpha$ and $\beta$ are coefficients to be estimated.

For our analyses of individual student outcomes, we specify similar models. Let $Y_{i, s, y}$ represent an outcome (attendance or test performance) for student $i$ at school $s$ in year $y$. Let $Z_{i, s, y}$ be a set of observed studentspecific characteristics, let $\psi_{y}$ be a set of unmeasured period-specific characteristics, let $\mu_{i}$ be a set of unmeasured time-invariant characteristics of the student (student fixed effects), and let $\nu_{i, s, y}$ represent other unmeasured time-varying and student-specific characteristics. For the student-specific outcomes, we estimate models of the form

$$
Y_{i, s, y}=\delta U_{s, t}+\gamma Z_{i, s, y}+\psi_{y}+\mu_{i}+\nu_{i, s, y} .
$$

We operationalize specifications (2) and (3) as two-way fixed-effects models.

The principal advantage of the fixed-effects models is that they control for unobserved time- and either school- or individual-specific characteristics that might be associated with both student outcomes and the school breakfast policy. The time fixed effects account for things like system-wide curricular initiatives and general economic and social conditions. The school fixed effects account for the general conditions of the schools, such as the physical facilities, the characteristics of the teachers, and the general administration of the schools, while the student fixed effects account for students' abilities and household attitudes.

\section{MEAL PARTICIPATION}

Table 3 reports coefficient estimates from the multivariate models of the associations between universal free breakfast provision and the monthly school-level meal participation outcomes. The top rows in table 3 list es- 
TABLE 3. Monthly Meal Participation Regression Results for Guilford County Change and Comparison Schools

\begin{tabular}{|c|c|c|c|c|c|c|c|c|}
\hline & \multicolumn{4}{|c|}{ SBP Participation } & \multicolumn{4}{|c|}{ Lunch Participation } \\
\hline & Total & $\begin{array}{c}\text { Free } \\
\text { Eligible }\end{array}$ & $\begin{array}{c}\mathrm{RP} \\
\text { Eligible }\end{array}$ & $\begin{array}{l}\text { Paid } \\
\text { Eligible }\end{array}$ & Total & $\begin{array}{c}\text { Free } \\
\text { Eligible }\end{array}$ & $\begin{array}{c}\mathrm{RP} \\
\text { eligible }\end{array}$ & $\begin{array}{l}\text { Paid } \\
\text { Eligible }\end{array}$ \\
\hline \multicolumn{9}{|c|}{$\begin{array}{l}\text { Models estimated with } \\
\text { school, month, and } \\
\text { year controls: }\end{array}$} \\
\hline Universal free SBP & $\begin{array}{l}.124^{* *} \\
(.055)\end{array}$ & $\begin{array}{l}.088 \\
(.049)\end{array}$ & $\begin{array}{l}.158^{*} \\
(.080)\end{array}$ & $\begin{array}{l}.276^{* * *} \\
(.092)\end{array}$ & $\begin{array}{r}-.003 \\
(.015)\end{array}$ & $\begin{array}{r}-.024 \\
(.016)\end{array}$ & $\begin{array}{l}.016 \\
(.038)\end{array}$ & $\begin{array}{l}.100 \\
(.073)\end{array}$ \\
\hline $2008-9$ & $\begin{array}{l}.031^{*} \\
(.016)\end{array}$ & $\begin{array}{l}.007 \\
(.018)\end{array}$ & $\begin{array}{l}.092^{\star * \star} \\
(.026)\end{array}$ & $\begin{array}{l}.155^{\star * *} \\
(.046)\end{array}$ & $\begin{array}{c}-.001 \\
(.010)\end{array}$ & $\begin{array}{c}-.025^{* *} \\
(.010)\end{array}$ & $\begin{array}{l}.057^{* *} \\
(.025)\end{array}$ & $\begin{array}{c}.123^{*} \\
(.057)\end{array}$ \\
\hline $\begin{array}{l}R^{2} \\
\text { Models estimated wit } \\
\text { school, month, y } \\
\text { and student den } \\
\text { graphic controls }\end{array}$ & .874 & .838 & .769 & .800 & .511 & .334 & .446 & .551 \\
\hline Universal free SBP & $\begin{array}{l}.164^{* *} \\
(.054)\end{array}$ & $\begin{array}{l}.133^{* *} \\
(.046)\end{array}$ & $\begin{array}{l}.209^{* *} \\
(.085)\end{array}$ & $\begin{array}{l}.275^{\star *} \\
(.101)\end{array}$ & $\begin{array}{c}.022 \\
(.013)\end{array}$ & $\begin{array}{c}.001 \\
(.015)\end{array}$ & $\begin{array}{r}-.007 \\
(.015)\end{array}$ & $\begin{array}{c}.129^{*} \\
(.063)\end{array}$ \\
\hline $2008-9$ & $\begin{array}{c}-.005 \\
(.033)\end{array}$ & $\begin{array}{c}-.026 \\
(.031)\end{array}$ & $\begin{array}{l}.025 \\
(.050)\end{array}$ & $\begin{array}{l}.135^{*} \\
(.067)\end{array}$ & $\begin{array}{c}-.001 \\
(.016)\end{array}$ & $\begin{array}{r}-.022 \\
(.017)\end{array}$ & $\begin{array}{l}.047^{*} \\
(.021)\end{array}$ & $\begin{array}{l}.126 \\
(.084)\end{array}$ \\
\hline$R^{2}$ & .899 & .868 & .806 & .816 & .616 & .383 & .531 & .595 \\
\hline
\end{tabular}

Note.-Coefficients and standard errors (in parentheses) estimated from ordinary least squares models with school and month fixed effects. Models estimated for four change and six comparison schools each contributing 18 monthly observations (180 observations total). Student demographic controls include percentages black, Hispanic, female, free-meal eligible, and reduced-price (RP) eligible. Standard errors account for clustering within schools. SBP $=$ School Breakfast Program.

* Significant at $10 \%$.

** Significant at $5 \%$.

*** Significant at $1 \%$.

timates from models that only account for general school, month, and year fixed effects. These specifications are essentially summaries of the descriptive results from table 2 . The principal distinction is that instead of reporting several difference-in-difference results, the model reports one, with the changes in participation that are associated with adding or removing a universal free program restricted to be symmetric. The estimates indicate that the universal free breakfast provision is associated with approximately a 12 percent increase in all-student breakfast participation. In the analyses of specific eligibility groups, the provision of universal free breakfasts is associated with a 9 percent increase in SBP participation among free-eligible children, a 16 percent increase in participation among reducedprice-eligible children, and a 28 percent increase in participation among paid-eligible children. The coefficients in the free-eligible model fall short of being statistically significant, but the coefficients in the reduced-price and paid-eligible models are distinguishable from zero. 
The bottom rows of table 3 list estimates from models that add controls for the race/ethnicity, gender, and eligibility composition of the students. As table 1 shows, these characteristics do not change much within our schools over the 2 years of the study. Including the measures modestly improves the fit of each model and leads to estimated associations between operating a universal free SBP and breakfast participation that are stronger than the models without observed controls. ${ }^{11}$ The coefficients for universal free provision for the all-student, free-eligible, and reduced-price-eligible breakfast participation outcomes are each about one-third larger when demographic and economic controls are added, while the coefficient for paideligible participation is unchanged. All of the coefficients remain statistically distinguishable from zero.

As with the descriptive analyses, universal free breakfast provision is not consistently associated with lunch participation. The coefficient in the all-student participation model is zero when controls are omitted but small and positive when controls are added. If we focus on the models with controls for students' demographic and economic characteristics, the provision of universal free breakfasts is associated with an increase in lunch participation among paid-eligible students but not among free- or reducedprice-eligible students. The positive association would be consistent with the idea that exposure to breakfasts may cause some paid-eligible students or their families to become more accepting of school meals generally.

\section{ATTENDANCE}

Results from multivariate analyses of the association between universal free breakfast provision and the monthly grade-level attendance rates are reported in table 4 . As with the analyses of meal participation, the models of attendance outcomes include controls for school-, year-, and monthspecific effects. Because the attendance figures are reported separately by grade, the models also include controls for grade-specific effects. The estimates listed in column 1 are from restricted models that include these controls only. The estimates listed in columns 2 and 3 are from models that add controls for the demographic and economic characteristics of the schools' students. The models in columns 2 and 3 have the same types of

11. Despite the change in the fit statistic, the coefficients on the observed controls are individually insignificant. This is due to the limited longitudinal variation and high degree of multicollinearity in the measures when school fixed effects are also included. 
TABLE 4. Monthly Grade-Level Attendance Regression Results for GCS Change and Comparison Schools

\begin{tabular}{lccc}
\hline & $\mathbf{( 1 )}$ & $\mathbf{( 2 )}$ & $\mathbf{( 3 )}$ \\
\hline Universal free SBP & -.002 & -.002 & -.003 \\
& $(.003)$ & $(.002)$ & $(.002)$ \\
$2008-9$ & .001 & .001 & .002 \\
& $(.002)$ & $(.001)$ & $(.002)$ \\
School fixed effects & Yes & Yes & Yes \\
Month fixed effects & Yes & Yes & Yes \\
Grade fixed effects & Yes & Yes & Yes \\
Student characteristics set 1 & No & No & No \\
Student characteristics set 2 & No & .557 & Yes \\
$R^{2}$ & .545 & .561 \\
\hline
\end{tabular}

Note.-Coefficients and standard errors (in parentheses) estimated from ordinary least squares models with school, month, and grade fixed effects. The models are estimated for four change and six comparison schools each contributing 18 monthly observations on five grades ( 900 observations total). Student demographic controls include percentages black, Hispanic, and female. Control set 1 also includes Guilford County Schools (GCS) supplied free-meal-eligible and reduced-price-eligible student percentages, while control set 2 includes North Carolina Department of Public Instruction supplied economically disadvantaged percentages. Standard errors account for clustering within schools. SBP = School Breakfast Program.

controls but use controls from different data sources. The model in column 2 uses the proportion of economically disadvantaged students that was reported by the GCS, while the model in column 3 uses the proportion reported by the NCDPI.

The coefficient estimate for universal free breakfast provision in the restricted model in table 4 , column 1 , indicates that such provision was associated with lower attendance, although the coefficient is imprecisely estimated and cannot be distinguished from zero. Similar results appear in the models that add demographic and economic controls.

Table 5 lists results from regression analyses of the student-level data from the NCERDC. An advantage of these data is that we can include student-level controls in the models. The top panel of table 5 reports results from models estimated using data on all first through fifth graders at the analysis schools. Column 1 lists results from a model that only includes school and grade controls. Column 2 lists results from a model that adds controls for students' demographic characteristics, while column 3 lists results from a model that includes student fixed effects. Results from all three specifications indicate that universal free breakfast provision is associated with a half percent decrease in attendance, equivalent to the loss of almost a full day over the school year. However, only the coefficients in column 3 are statistically distinguishable from zero. 
TABLE 5. Student-Level Attendance Regression Results for Guilford County Change and Comparison Schools

(1) (2) (3)

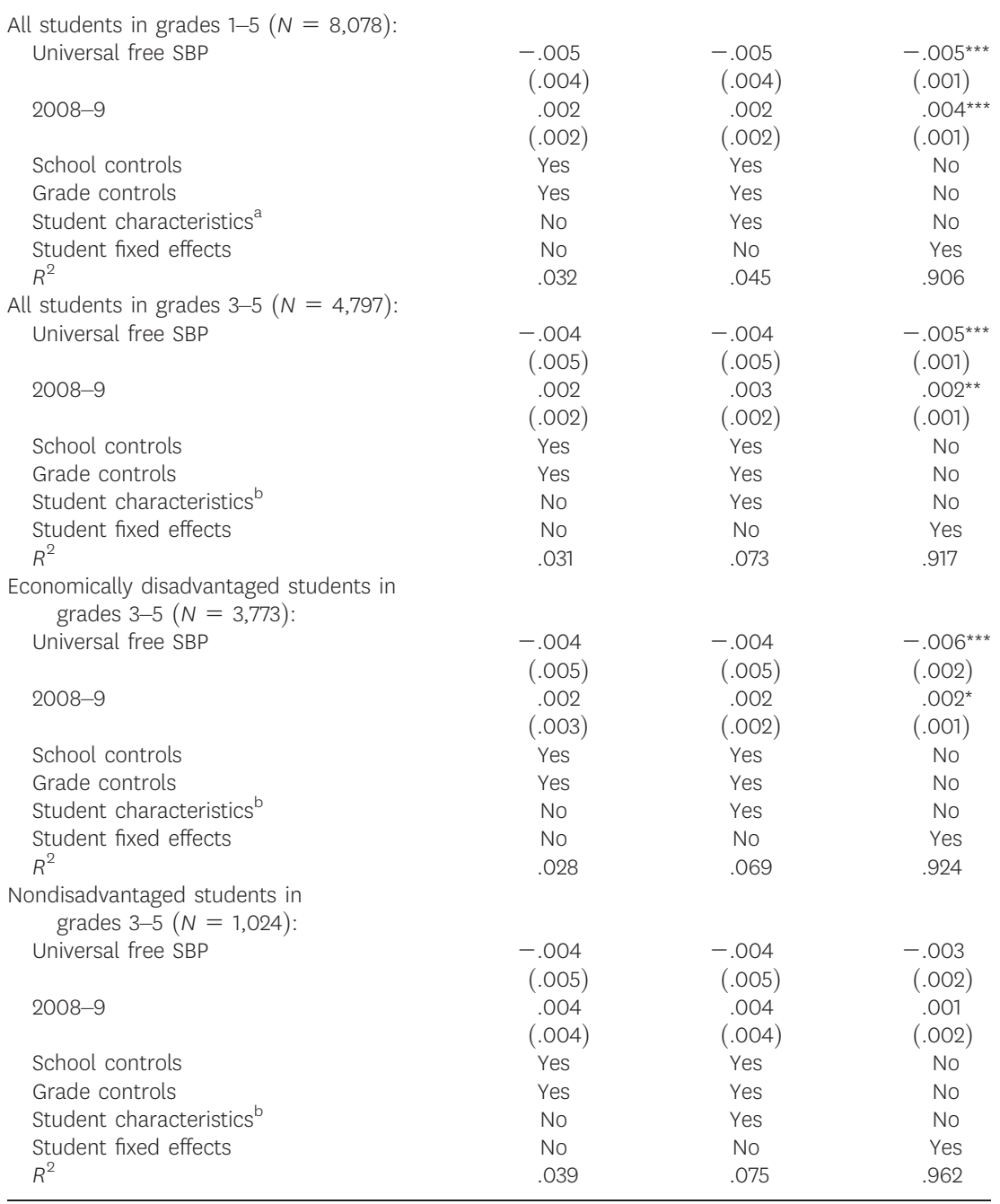

Note.-Coefficients and standard errors (in parentheses) estimated from ordinary least squares models with school and grade fixed effects. Models estimated for four change and six comparison schools. Standard errors account for clustering by school (cols. 1 and 2) or student (col. 3). SBP = School Breakfast Program.

a Controls for student characteristics include indicators for gender and black, Hispanic, or other nonwhite race/ethnicity.

b Controls for student characteristics include indicators for gender; black, Hispanic, or other nonwhite race/ethnicity; economic disadvantage; limited English proficiency; math or reading giftedness; and exceptionalness (disability).

* Significant at $10 \%$.

** Significant at $5 \%$.

*** Significant at $1 \%$. 
The NCERDC data for the first and second graders only have a limited set of covariates. More measures, including controls for economic disadvantage, limited English proficiency, giftedness, and exceptionality, are available for the older students who were subject to testing. The second panel of table 5 reports results from models estimated using these older students. The specifications for these models are similar to those from the first panel, except that we included the additional controls in the model in column 2 . The coefficients for all three specifications are negative and similar in magnitude to the coefficients in the top panel. As with the top panel, only the coefficient in the student fixed-effects model is statistically significant.

The negative association between universal free breakfast provision and attendance is something of a puzzle, although the study by Peterson and colleagues (2004) also finds a modest negative association. Universal free provision has such a strong positive association with breakfast participation, which can only occur if more students show up in the cafeteria in the morning. Two explanations might reconcile these results. The first potential explanation is that the increased use of school breakfasts may interfere with families' morning routines. For example, parents and children living in households that depend on school breakfasts may sleep later in the morning, increasing the risk that children miss their school buses. ${ }^{12}$ Alternatively, the structure of a regular morning meal may help parents and children to organize their time. Ashlesha Datar and Nancy Nicosia (2012) report that elementary students are more likely to eat breakfast at home, rather than school, if their mothers work. A second potential explanation is that participating in the SBP may increase children's exposure to colds and the flu. Simon Cauchemez and colleagues (2011) studied a $2009 \mathrm{H} 1 \mathrm{N1} \mathrm{flu}$ outbreak in an elementary school in Pennsylvania and find that class structure and children's play patterns are important factors for transmission. Calatayud and colleagues (2010) conducted a case study of an outbreak of the same flu strain in a London school and found that class structure and attendance at a large social event may have spread transmission. At lunch

12. Consider the schedules of two children living in separate households who differ in their SBP participation. Assume that each child requires 30 minutes to rise, wash, dress, and gather things for school and 15 minutes to eat a meal. Suppose that because of these requirements, the child who participates in the SBP typically wakes up 30 minutes before the school bus arrives, while the child who does not participate in the SBP typically wakes up 45 minutes before the bus arrives. If something goes wrong (e.g., an alarm fails or a child oversleeps), the SBP participant will have 15 fewer minutes to recover than the nonparticipant and be at higher risk of missing her bus. 
time in the schools we study, students generally stand in line and sit with their own class, so exposure to illness would not be much greater than in the classroom and would not be much affected by meal participation. During breakfast, however, students get into the meal line as they arrive at school and are free to sit with children who are not their classmates, which could increase exposure and contagion rates. One piece of evidence supporting this potential explanation is that the attendance differentials in the data were highest during the winter months.

The bottom two panels of table 5 list results from models of attendance rates that are estimated separately for third through fifth graders who qualified for free and reduced-price meals (were economically disadvantaged) and who did not qualify for these subsidies. One reason for dividing the students this way is that economically disadvantaged students tend to have lower attendance rates than more advantaged students. Another reason is that breakfast participation among the disadvantaged students is less responsive to the provision of universal free breakfasts than participation among other students. If changes in students' own breakfast participation are directly responsible for their changes in attendance, such as by interfering with family routines, we might see larger attendance associations among the nondisadvantaged students. As it turns out, no such effect is apparent. In the models with only school and grade controls and the models that include observed student characteristics, the estimated associations between universal free breakfast provision and attendance are identical. When student-specific effects are included in column 3, the results diverge, with the association for economically disadvantaged students becoming especially negative and the association for nondisadvantaged students losing its significance. At a minimum, the pattern of results suggests that the attendance associations are not monotonically tied to students' own breakfast participation. This could arise if economically disadvantaged students just respond differently or if the effects of universal free breakfast provision are indirect, such as by increasing exposure to illnesses. However, the results could also indicate that the attendance changes are a statistical artifact.

\section{TEST SCORES}

Table 6 reports regression results from models estimated using studentlevel test data. We examine binary indicators of whether the students achieved proficiency in math, reading, and science and continuous measures of test scores for the students who took the general versions of these tests. 
The results in the top row of table 6 are from restricted models that only include controls for schools, grades, and the year of the observation. The estimated associations of universal free breakfast provision and students' math and reading test outcomes are all small and statistically insignificant. For example, the point estimates on the math test results indicate that universal free breakfast provision is associated with a 1 percent increase in proficiency and a .07 standard deviation increase in the test score. Universal free breakfast provision is estimated to be associated with a marginally significant 7 percent increase in science proficiency but only a small (.1 standard deviation) and statistically insignificant increase in the science test score.

In the next rows of table 6, we report results from models that also included student-level controls for gender, race/ethnicity, meal subsidy status, limited English proficiency, giftedness, disability status, and days in school membership. The fit of the models improved markedly when these controls were added (the controls were jointly significant in all of the models). However, the estimated associations between universal free breakfast provision and the test outcomes are little changed from the restricted models. The models continue to indicate a marginally significant, 7 percentage point positive association with science proficiency rates and small, statistically insignificant associations with all of the other test outcomes.

Elementary school students take EOG reading and math tests each year, starting in the third grade. Thus, for children who were in the third or fourth grade in 2007-8 and who continued attending our analysis schools, we can estimate models for math and reading test outcomes that include student fixed effects. These models are useful because they control for many characteristics of students that might be hard to measure, such as students' general motivation and home environments. Estimates from student fixed-effects models of math and reading test results in the next rows of table 6 are qualitatively similar to the estimates from the more restrictive models and continue to indicate that there is little association between universal free breakfast provision and students' test outcomes. ${ }^{13}$

The availability of student-level controls in the NCERDC data also allows us to examine test outcomes separately for students who are and are not economically disadvantaged. The remaining rows in table 6 report results from models estimated separately for these two groups. The separate

13. It is not possible to estimate fixed-effects specifications for students' science test outcomes because students only take this test once while they are in elementary school. 


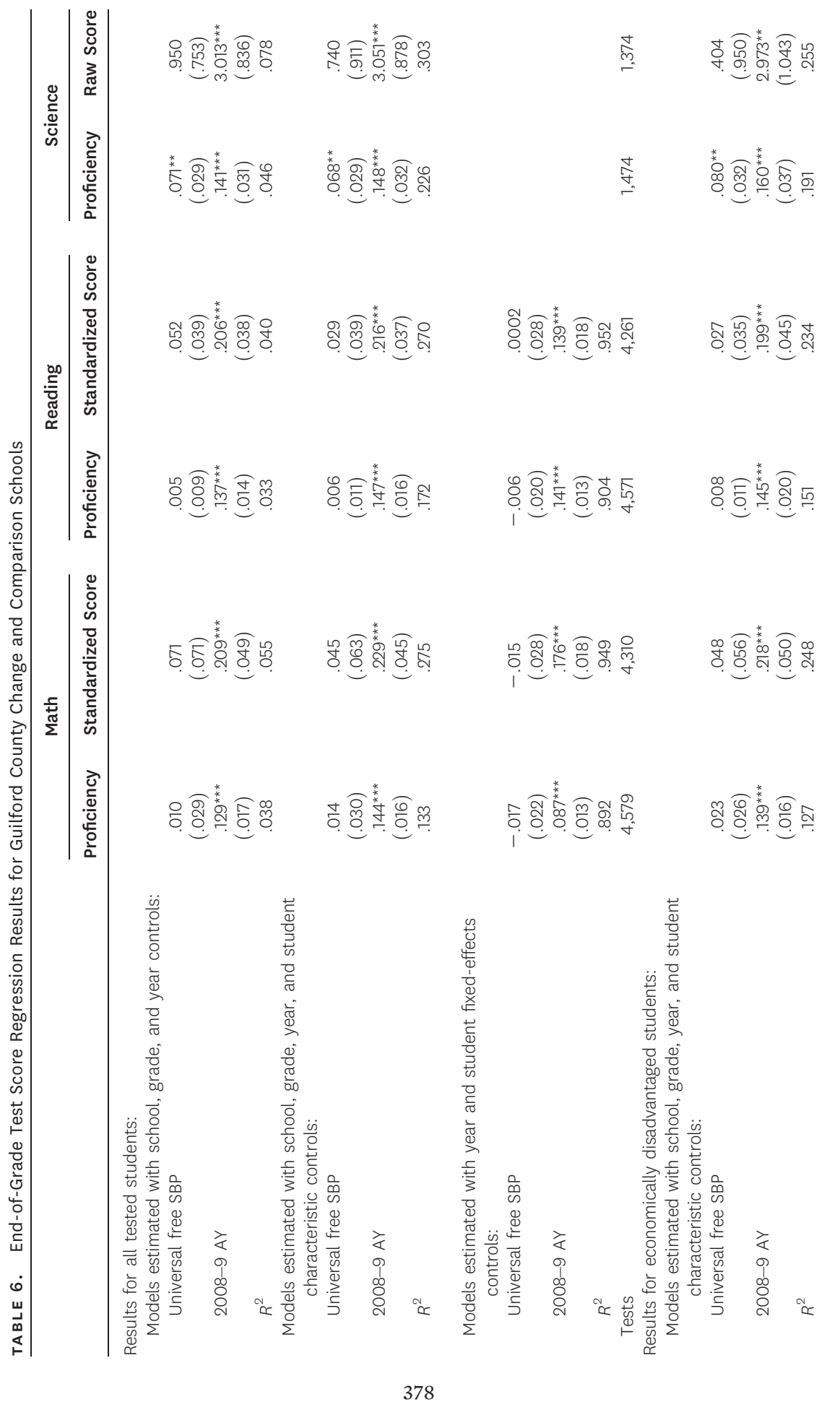




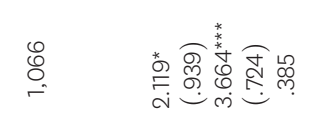

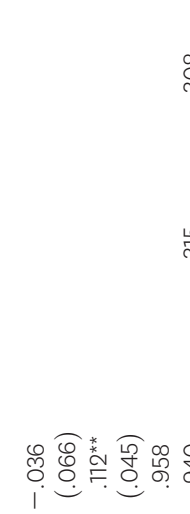

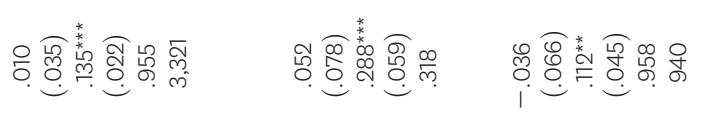

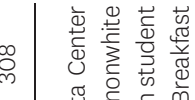

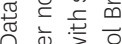

든 흥 $\frac{0}{0} \frac{}{0}$

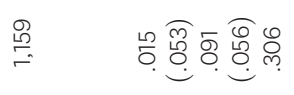

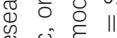

垴

등 항

尊

긍 猔

远

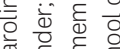

Uू.

녹 产 忿

2 잉

我

잉

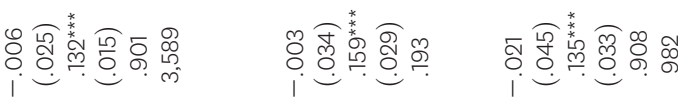

웡

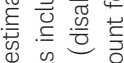

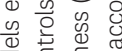

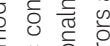

绖

这离通

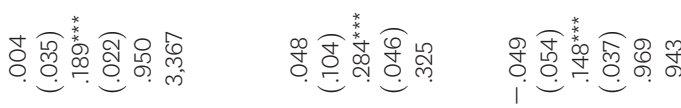

क्ष

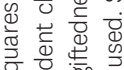

क

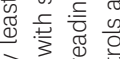

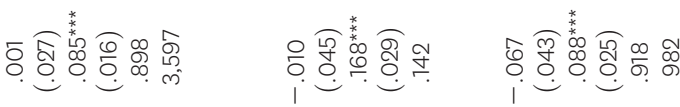

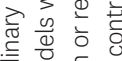

항 巳

है

जी है

ه广

告

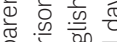

웜

हो

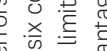

政

品

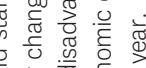

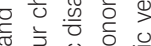

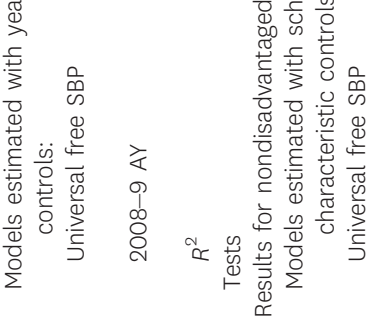

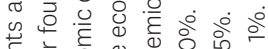

क्षे 흔

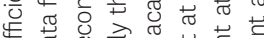

娄 $\frac{0}{0}$ 专

1.

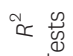

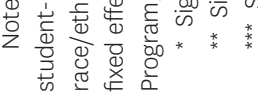

379 
models, however, do not lead to substantive changes in the results. There is no evidence for either group that universal free breakfast provision is associated with reading or math test results or with science raw scores. Universal free breakfast provision continues to be associated with science test proficiency among economically disadvantaged children but not among other children.

\section{CONCLUSION}

In this article, we examine how students' school meal participation, attendance, and test performance changed after the Guilford County School system in North Carolina changed the way that several of its Title I elementary schools operated their school breakfast programs. In particular, three schools that had been serving breakfasts on a universal free basis changed to less generous eligibility-based programs, while one school that operated an eligibility-based program initiated a universal free program. The changes in provision had features of a natural experiment and thus represent a nearly exogenous source of variation. To further identify causal effects, our analyses employ a difference-in-difference methodology in which we examine outcomes at schools in the year before and the year after the breakfast programs changed and at schools that did and did not experience these changes. For the nonchanging schools, we consider schools that are exactly comparable to the changing schools in terms of their calendars, programs, Title I status, and geography and mostly comparable in their student characteristics. Our study also relies on administrative, rather than self-reported, sources of data.

These analytical advantages notwithstanding, there are limitations; the study only considers a small number of schools in a single school district. The small number of schools reduces the statistical power of the analyses, although we are able to estimate significant relationships for several outcomes. The restriction to a single school system, even a large, diverse, and predominantly urban system like the GCS, limits the generalizability of the results and increases the susceptibility to one-off, random shocks.

The analyses reveal that breakfast participation rates fell substantially at the schools that switched to eligibility-based programs and rose just as substantially at the school that switched to a universal free program. Although we hypothesized that the participation responses might be faster at schools that lost universal free programs than at schools that gained them, the estimated responses were nearly symmetric at the two types of 
schools. In each case, universal free breakfast provision was associated with a 12-16 percent increase in SBP participation.

There were differences in participation between different types of students. Participation changed the most for the students who faced the largest change in their effective costs - students who were not otherwise eligible for free or reduced-price meals. However, participation also changed substantially for students who qualified for free meals. The latter result is consistent with universal free SBP provision reducing the stigma associated with participating in the SBP.

We also examine participation in the school lunch program at the schools. We find some evidence that changing from a universal free SBP to an eligibility-based program was associated with lower lunch participation among paid-eligible students, another result that seems consistent with universal free programs reducing the stigma or improving the perceptions of school meals. Lunch participation among free- and reduced-price-eligible students was not changed, and because paid-eligible students were only a small fraction of the students at our study schools, overall lunch participation was little changed.

Our analyses of attendance lead to an unexpected, albeit tentative, finding: schools that switched from universal free to eligibility-based SBPs experienced small gains in attendance. We examine attendance using two different data sources: monthly grade-level data for each school and confidential student-level data. Similar findings appear in both sources, but we are only able to obtain precise results with the student-level data. Although the result is unexpected, it is not unprecedented; Peterson and colleagues (2004) report a similar result. The difference that we find is small; it works out to about 1 day a year in attendance. We speculate that school breakfast participation may interfere with families' morning routines, possibly leading some children to miss transportation connections. Breakfast participation may also increase children's exposure to contagious illnesses. When we examine attendance on a month-by-month basis, the largest differences appear in the winter months when colds and flu are especially prevalent. Also, the attendance changes are largest for economically disadvantaged students, students whose breakfast participation changed the least, which suggests an indirect effect, perhaps through illnesses. Given the tentative nature of this finding, it should be a focus of further study.

We find little evidence that universal free breakfast provision changed students' standardized test performance. Over the period that we study, test results across our analysis schools improved markedly. The improve- 
ments were generally just as strong at the elementary schools that lost, gained, and did not change universal free breakfast programs. One area in which there might have been an association was in fifth graders' science scores, which appeared to be positively related to universal free breakfast provision. We do not place much confidence in this result, however, because it was limited to one measure of test performance and not robust when using another measure. Also, science tests are administered less frequently than the other math and reading tests that we examine; because of this, we could not implement some of the more rigorous statistical techniques for science tests that we could with the other tests.

The available evidence points to large changes in school breakfast participation but few academic harms, either in terms of attendance or standardized test results, from the GCS decision to scale back its universal free breakfast programs. These findings are consistent with those of other recent careful studies of universal free programs. The absence of academic harms may be explained by families substituting household breakfasts for schoolprovided breakfasts and relatively few children actually going without breakfast. At the same time, it is important to acknowledge other nonacademic harms that may have accompanied the change, including economic losses for the families that began providing breakfasts and increased stigma for the children that continued participating in the program. The ability to maintain academic performance under such challenging circumstances may attest to families' and individual children's resilience.

\section{APPENDIX}

\begin{tabular}{lcc}
\hline TABLE A1. Sources of Data & & \\
\hline Source/Measure & Unit of Observation & Periodicity \\
\hline $\begin{array}{l}\text { GCS School Nutrition Services office: } \\
\text { Number of breakfasts served (total and by }\end{array}$ & & \\
$\quad$ free, reduced-price, and paid-eligible & & Monthly \\
status) & School & \\
Number of lunches served (total and by & & Monthly \\
free, reduced-price, and paid-eligible & & Annual \\
status) & School & Annual \\
$\%$ students free eligible & School & \\
\% students reduced-price eligible & School & Annual \\
Students in daily membership (for & & Monthly \\
participation rate calculations) & School & Annual
\end{tabular}


TABLE A1. (continued)

\begin{tabular}{|c|c|c|}
\hline Source/Measure & Unit of Observation & Periodicity \\
\hline Title I status* & School & Annual \\
\hline \multicolumn{3}{|l|}{ Calendars, programs, and SACS } \\
\hline accreditation* & School & Annual \\
\hline City* & School & $\ldots$ \\
\hline \multicolumn{3}{|l|}{$\begin{array}{l}\text { North Carolina Department of Public } \\
\text { Instruction: }\end{array}$} \\
\hline Average daily membership & School & Annual \\
\hline$\%$ students black & School & Annual \\
\hline \% students Hispanic & School & Annual \\
\hline$\%$ students female & School & Annual \\
\hline$\%$ students economically disadvantaged & School & Annual \\
\hline \multicolumn{3}{|l|}{ Attendance (days attending and in } \\
\hline membership) & Grade within school & Monthly \\
\hline \multicolumn{3}{|l|}{ Math, reading, and science test proficiency } \\
\hline rates & Grade within school & Annual \\
\hline $\begin{array}{l}\text { North Carolina Education Research Data } \\
\text { Center: }\end{array}$ & & \\
\hline \multicolumn{3}{|l|}{ Attendance (days attending and in } \\
\hline membership) & Student & Annual \\
\hline \multicolumn{3}{|l|}{ Math, reading, and science test and } \\
\hline proficiency scores & Student & Annual \\
\hline School & Student & Annual \\
\hline Grade & Student & Annual \\
\hline Gender & Student & Annual \\
\hline Black & Student & Annual \\
\hline Hispanic & Student & Annual \\
\hline Other nonwhite race/ethnicity & Student & Annual \\
\hline Economically disadvantaged & Student & Annual \\
\hline Limited English proficiency & Student & Annual \\
\hline Math or reading gifted & Student & Annual \\
\hline Exceptional (disabled) & Student & Annual \\
\hline
\end{tabular}

\section{NOTE}

David C. Ribar is a professor in the Department of Economics at the University of North Carolina at Greensboro and a research fellow at the Institute for the Study of Labor in Bonn, Germany.

Lauren A. Haldeman is an associate professor in the Department of Nutrition at the University of North Carolina at Greensboro.

The authors gratefully acknowledge financial support from the Economic Research Service of the US Department of Agriculture (USDA) under Food Assistance and Nutrition Research Program Cooperative Agreement no. 58-5000-8-0124. They also thank the North Carolina Education Research Data Center (NCERDC) for providing student-level data on test scores 


\section{Social Service Review}

and attendance. In addition, the authors thank Theresa Brumfit, Sara Himmelrich, Joanne Guthrie, Megan Larson, Constance Newman, Cynthia Sevier, and Gongshu Zhang for their assistance. They also thank Melayne McInnes, Amit Sharma, and three anonymous reviewers for comments. The views expressed in this article are those of the authors and do not necessarily reflect those of the USDA, the NCERDC, or the Guilford County Schools.

\section{REF E R E N C E S}

Bartlett, Susan, Frederic Glantz, and Christopher Logan. 2008. School Lunch and Breakfast Cost Study II: Final Report. Special Nutrition Programs Report no. CN-08-MCII. Alexandria, VA: USDA Food and Nutrition Service.

$\rightarrow$ Belot, Michèle, and Jonathan James. 2011. "Healthy School Meals and Educational Outcomes." Journal of Health Economics 30:489-504.

Bernstein, Lawrence S., John E. McLaughlin, Mary K. Crepinsek, Lynn M. Daft, and J. Michael Murphy. 2004. Evaluation of the School Breakfast Program Pilot Project: Final Report. Special Nutrition Programs Report no. CN-04-SBP. Alexandria, VA: USDA Food and Nutrition Service.

$\rightarrow$ Calatayud, L., S. Kurkela, P. E. Neave, A. Brock, S. Perkins, M. Zuckerman, M. Sudhanva, A. Bermingham, J. Ellis, R. Pebody, M. Catchpole, R. Heathcock, and H. Maguire. 2010. "Pandemic (H1N1) 2009 Virus Outbreak in a School in London, April-May 2009: An Observational Study." Epidemiology and Infection 138:183-91.

$\rightarrow$ Cauchemez, Simon, Achuyt Bhattarai, Tiffany L. Marchbanks, Ryan P. Fagan, Stephen Ostroff, Neil M. Ferguson, David Swedlow, and the Pennsylvania H1N1 Working Group. 2011. "Role of Social Networks in Shaping Disease Transmission during a Community Outbreak of 2009 H1N1 Pandemic Influenza." Proceedings of the National Academy of Sciences 108:2825-30.

Connell, David, and Mary K. Fox. 2004. "School Breakfast Program." In Effects of Food Assistance and Nutrition Programs on Nutrition and Health, vol. 3, Literature Review, edited by Mary K. Fox, William Hamilton, and Biing-Hwan Lin. Food Assistance and Nutrition Research Report no. 19-3. Washington, DC: USDA Economic Research Service.

$\rightarrow$ Datar, Ashlesha, and Nancy Nicosia. 2012. "Outsourcing Meals: Effects of Maternal Work on Children's School Meal Participation.” Social Service Review 86:565-93.

$\rightarrow$ Figlio, David N., and Joshua Winicki. 2005. "Food for Thought: The Effects of School Accountability Plans on School Nutrition.” Journal of Public Economics 89:381-94.

Glantz, Frederic B., Regina Berg, Diane Porcari, Ellen Sackoff, and Shelley Pazer. 1994. School Lunch Eligible Nonparticipants: Final Report. Washington, DC: USDA Food and Nutrition Service.

Haldeman, Lauren A., Sara S. Himmelrich, and David C. Ribar. 2011. Process Analysis of Changes in Universal-Free School Breakfast Programs in Guilford County, NC. Contractor and Cooperator Report no. 73-1. Washington, DC: USDA Economic Research Service.

$\rightarrow$ Hoyland, Alexa, Louise Dye, and Clare L. Lawton. 2009. "A Systematic Review of the Effect of Breakfast on the Cognitive Performance of Children and Adolescents." Nutrition Research Reviews 22:220-43. 
Kleinman, Ronald E., S. Hall, H. Green, D. Korzec-Ramirez, K. Patton, Maria E. Pagano, and J. Michael Murphy. 2002. "Diet, Breakfast, and Academic Performance in Children." Annals of Nutrition and Metabolism 46:24-30.

Leos-Urbel, Jacob, Amy E. Schwartz, Meryle Weinstein, and Sean Corcoran. 2011. "Not Just for Poor Kids: The Impact of Universal Free School Breakfast on Meal Participation and Student Outcomes.” Unpublished manuscript. New York University.

$\rightarrow$ Murphy, J. Michael, Mary E. Pagano, Joan Nachmani, Peter Sperling, Shirley Kane, and Ronald E. Kleinman. 1998. "The Relationship of School Breakfast to Psychosocial and Academic Functioning." Archives of Pediatric and Adolescent Medicine 152:899-907.

$\rightarrow$ Murphy, Simon, G. F. Moore, K. Tapper, R. Lynch, R. Clarke, L. Raisanen, C. Desousa, and L. Moore. 2011. "Free Healthy Breakfasts in Primary Schools: A Cluster Randomised Controlled Trial of a Policy Intervention in Wales, UK." Public Health Nutrition 14:219-26.

NCDPI (North Carolina Department of Public Instruction). 2011. The North Carolina State Testing Results: “The Green Book.” Raleigh, NC: Public Schools of North Carolina.

Peterson, Kristin, Mark L. Davison, Kyla Wahlstrom, John Himes, Mary Stevens, Young S. Seo, Margaret L. Irish, Kristine Holleque, Jeffrey Harring, and Anastasia Hansen. 2004. Fastbreak to Learning School Breakfast Program: A Report of the Fourth Year Results, 2002-03. Minneapolis: University of Minnesota.

Rainville, Alice J., and Deborah H. Carr. 2008. "In-Classroom Breakfast: Best Practices in Three School Districts.” Journal of Child Nutrition and Management 32, no. 2. http://www .schoolnutrition.org/Content.aspx?id=10604.

$\rightarrow$ Rampersaud, Gail C., Mark A. Pereira, Beverly L. Girard, Judi Adams, and Jordan D. Metzl. 2005. "Breakfast Habits, Nutritional Status Body Weight, and Academic Performance in Children and Adolescents." Journal of the American Dietetic Association 105:743-60.

Ribar, David C., and Lauren A. Haldeman. 2011. Universal-Free and Eligibility-Based School Breakfast Programs in Guilford County, North Carolina: Student Outcomes. Contractor and Cooperator Report no. 73-2. Washington, DC: USDA Economic Research Service.

$\rightarrow$ Roustit, Christelle, Anne-Marie Hamelin, Francesca Grillo, Judith Martin, and Pierre Chauvin. 2010. "Food Insecurity: Could School Food Supplementation Help Break Cycles of Intergenerational Transmission of Inequalities?” Pediatrics 126:1174-81.

US Agricultural Research Service. 2010. "Breakfast: Percentages of Selected Nutrients Contributed by Foods Eaten at Breakfast, by Family Income (as \% of Federal Poverty Threshold) and Age." In What We Eat in America. National Health and Nutrition Examination Survey, 2007-2008. Washington, DC: US Department of Agriculture. Last modified August. http://www.ars.usda.gov/SP2UserFiles/Place/12355000/pdf/0708/Table_16_BRK_POV_07 .pdf.

US Economic Research Service. 2010. "The Food Assistance Landscape: FY 2009 Annual Report.” Economic Information Bulletin no. 6-7. Washington, DC: USDA Economic Research Service.

US Food and Nutrition Service. 2001. "National School Lunch Program and School Breakfast Program: Alternatives to Standard Application and Meal Counting Procedures, Final Rule.” 66 Fed. Reg. 48323-34. 